Article

\title{
The Effect of a Multiphase Microstructure on the Inverse Magnetocaloric Effect in Ni-Mn-Cr-Sn Metamagnetic Heusler Alloys
}

\author{
Paweł Czaja ${ }^{1, *}$, Robert Chulist ${ }^{1}$, Antoni Żywczak ${ }^{2}$, Lukasz Hawelek ${ }^{3}$ and Janusz Przewoźnik ${ }^{4}$ \\ 1 Institute of Metallurgy and Materials Science, Polish Academy of Sciences, 25 Reymonta St., 30-059 Krakow, \\ Poland; r.chulist@imim.pl \\ 2 AGH University of Science and Technology, Academic Centre of Materials and Nanotechnology, \\ Al. Mickiewicza 30, 30-059 Kraków, Poland; zywczak@agh.edu.pl \\ 3 Institute of Non-Ferrous Metals, 5 Sowinskiego Str., 44-100 Gliwice, Poland; lukasz.hawelek@gmail.com \\ 4 Department of Solid State Physics, Faculty of Physics and Applied Computer Science, \\ AGH University of Science and Technology, Al. Mickiewicza 30, 30-059 Kraków, \\ Poland; januszp@agh.edu.pl \\ * Correspondence: p.czaja@imim.pl; Tel.: +48-12-295-28-82
}

Received: 11 April 2017; Accepted: 29 June 2017; Published: 6 July 2017

\begin{abstract}
Two Ni-Mn-Sn alloys substituted with 0.5 and 1 at.\% Cr have been studied. The first alloy shows an average composition of $\mathrm{Ni}_{49.6} \mathrm{Mn}_{37.3} \mathrm{Cr}_{0.7} \mathrm{Sn}_{12.4}(\mathrm{e} / \mathrm{a}=8.107)$, whereas the second has a multiphase microstructure with the matrix phase of an average $\mathrm{Ni}_{52.4} \mathrm{Mn}_{32.7} \mathrm{Cr}_{1} \mathrm{Sn}_{14}$ composition $(e / a=8.146)$. Both alloys undergo a reversible martensitic phase transformation. The $\mathrm{Ni}_{49.6} \mathrm{Mn}_{37.3} \mathrm{Cr}_{0.7} \mathrm{Sn}_{12.4}$ alloy transforms to the martensite phase at $239 \mathrm{~K}$ and, under the magnetic field change of $\mu_{0} \cdot \Delta H=1.5 \mathrm{~T}$, gives the magnetic entropy change equal to $7.6 \mathrm{~J} / \mathrm{kg} \cdot \mathrm{K}$. This amounts to a refrigerant capacity in the order of $48.6 \mathrm{~J} / \mathrm{kg}$, reducible by $29.8 \%$ due to hysteresis loss. On the other hand, the alloy with a multiphase microstructure undergoes the martensitic phase transformation at $223 \mathrm{~K}$ with the magnetic entropy change of $1.7 \mathrm{~J} / \mathrm{kg} \cdot \mathrm{K}(1 \mathrm{~T})$. Although the latter spreads over a broader temperature window in the multiphase alloy, it gives much smaller refrigerant capacity of $16.2 \mathrm{~J} / \mathrm{kg}$ when compared to $\mathrm{Ni}_{49.6} \mathrm{Mn}_{37.3} \mathrm{Cr}_{0.7} \mathrm{Sn}_{12.4}$. The average hysteresis loss for a field change of $1.5 \mathrm{~T}$ in the multiphase alloy is $2.7 \mathrm{~J} / \mathrm{kg}$, reducing the effective refrigerant capacity by $16.7 \%$. These results illustrate that the key to gaining a large effective refrigerant capacity is the synergy between the magnitude of the magnetic entropy change and its broad temperature dependence.
\end{abstract}

Keywords: magnetocaloric effect; Heusler alloys; martensitic transformation; Vibrating Sample Magnetometer

\section{Introduction}

Inverse magnetocaloric effect (MCE) inherent to Ni-Mn-(In, $\mathrm{Sn}, \mathrm{Sb}$ ) metamagnetic shape memory alloys (MMSMAs) relates to a peculiar magnetic entropy change $\left(\Delta S_{M}>0\right)$ in the proximity of the first order thermoelastic martensitic phase transformation (MPT) [1]. The $\Delta S_{M}$ change arises from the symmetry breaking concomitant with an abrupt magnetisation change upon MPT; this phenomenon is due to a unique coupling between the magnetic and structural degrees of freedom [2]. Large magnetic entropy changes on the order of $18 \mathrm{~J} / \mathrm{kg} \cdot \mathrm{K}$ under the magnetic field change of $\mu_{0} \cdot \Delta H=5 \mathrm{~T}$, in addition to a large elastocaloric effect $\left(\Delta T_{a d .}=4 \mathrm{~K}\right)$, have been recorded for the metamagnetic Ni-Mn-Sn system [3-5], which, aside from other functionalities [6,7] makes it intriguing for solid state refrigeration [8].

In order to maximise MCE and bring the working temperature (MPT) close to room temperature, the composition of MMSMAs is frequently modified. This approach relies on the sensitivity of the MPT 
temperature $\left(T_{M}\right)$ and, to a lesser extent, the Curie temperature of austenite $\left(T_{C}^{A}\right)$ to composition change in Ni-Mn based alloys; this sensitivity is often expressed in terms of the valence electron concentration $(e / a)[9,10]$. In general, experimental findings for MMSMAs reveal a growing instability of the $\beta$-phase towards closed, packed martensite with incremental $e / a$, which sends $T_{\mathrm{M}}$ upwards [10-12]. It has been consistently reported that, for instance, partial substitution of $\mathrm{Mn}$ by $\mathrm{Cr}$ in $\mathrm{Ni}_{45} \mathrm{Mn}_{44-x} \mathrm{Cr}_{x} \mathrm{Sn}_{11}$ at the level of $x=1$ and 2 at.\% results in a decrease in $T_{\mathrm{M}}$ and simultaneously for $x=1$ at.\% yields the maximum $\Delta S_{\mathrm{M}}=23.4 \mathrm{~J} / \mathrm{kg} \cdot \mathrm{K}$ at $240 \mathrm{~K}$ under the low magnetic field change of $1 \mathrm{~T}$ [13], which under $\mu_{0} \cdot \Delta H=5 \mathrm{~T}$ goes up to $35 \mathrm{~J} / \mathrm{kg} \cdot \mathrm{K}$ [14]. While promising, Cr for Mn substitution in metamagnetic $\mathrm{Ni}_{50} \mathrm{Mn}_{33} \mathrm{In}_{17}$ and $\mathrm{Ni}_{50} \mathrm{Mn}_{37} \mathrm{Sb}_{13}$ is found, conflictingly, to disobey monotonic $T_{M}$ vs. e/a dependence. Initially, with up to 2 at.\% $\mathrm{Cr}$ for Mn substitution, $T_{\mathrm{M}}$ is observed to increase despite decreasing $e / a$; then, at higher $\mathrm{Cr}$ concentration $T_{M}$ drastically decreases and is finally suppressed at $>5$ at. $\% \mathrm{Cr}$ [15-18]. Simultaneously, already at low $\mathrm{Cr}$ concentrations ( $\leq 2$ at.\%), the $\mathrm{Cr}$-rich precipitate phase is reported in $\mathrm{Ni}-\mathrm{Mn}-\mathrm{In}$, indicating poor $\mathrm{Cr}$ solubility in this ternary system with an overall limiting influence on the magnitude of the $\Delta S_{M}$ [17]. Although seemingly detrimental for MCE [19], phase inhomogeneity is not always undesirable, e.g., in the sense of ductility enhancement in $\mathrm{Co}-\mathrm{Ni}-(\mathrm{Ga}, \mathrm{Al})$ due to the small volume of a precipitated $\gamma$ phase [20], while more recently inhomogeneity has been reported to add to the plethora of existing functionalities in Ni-Mn-(Sn, In) MMSMA in terms of core-shell ferromagnetism [21]. Also regarding MCE inhomogeneity embodied by, e.g., a compositional gradient leading to a cascade of successive $T_{M}$ or $T_{C}{ }^{A}$ temperatures [22] and/or supposedly a certain degree of atomic disorder [23,24] may, in accordance with recent findings, turn out somewhat advantageous for MCE, stemming from the extended temperature dependence of the $\Delta S_{M}$ [25]. Thus, improving the efficiency of the Ericsson cycle, for example, due to the boost in the refrigerant capacity (RC), a critical parameter accounting for the effective cooling power (amount of heat transferred from the surrounding environment to the heat sink) of a prospective MMSMA refrigeration material.

Therefore, this paper examines the effect of a low amount of 0.5 and 1 at. $\% \mathrm{Cr}$ for Mn substitution in the $\mathrm{Ni}_{48} \mathrm{Mn}_{39.5} \mathrm{Sn}_{12.5}$ system, its effect on microstructure evolution and characteristic thermomagnetic behaviour. The $\Delta S_{\mathrm{M}}$ and RC are computed and discussed in the context of a multi-phase microstructure and mixed magnetic correlations.

\section{Experimental}

Two polycrystalline ingots with a nominal composition of $\mathrm{Ni}_{48} \mathrm{Mn}_{39.5-} \mathrm{Cr}_{x} \mathrm{Sn}_{12.5}$ ( $x=0.5,1$ at.\%), hereafter referred to as $0.5 \mathrm{Cr}$ and $1 \mathrm{Cr}$, were manufactured from high purity elements by conventional arc melting under protective Ar gas. The ingots were turned upside down and re-melted six times for homogeneity. They were then sealed under vacuum in quartz ampoules, placed in the furnace at $1070 \mathrm{~K}$ for $1 \mathrm{~h}$, followed by water quenching. Microstructure, phase and chemical composition were elaborated employing a FEI E-SEM XL30 scanning electron microscope (SEM) equipped with an energy-dispersive $X$-ray spectrometer (EDX). The structure has been confirmed with synchrotron high-energy X-ray radiation $(87.1 \mathrm{keV}, \lambda=0.142342 \AA)$ at the beamline Petra P07B at DESY, Germany. In addition, the room temperature $\mathrm{X}$-ray diffraction $(\mathrm{XRD})$ experiments were performed on powdered samples using a Rigaku-Denki D/MAX RAPID II-R diffractometer (Rigaku Corporation, Tokyo, Japan) equipped with a rotating $\mathrm{Ag}$ anode $(\lambda=0.5608 \AA)$, an incident beam (002) graphite monochromator and an image plate in the Debye-Scherrer geometry as a detector. The obtained data was analysed using the profile fitting program FullProf based on the Rietveld method. The background intensity was approximated with a polynomial and the peak shape was fitted with a pseudo-Voigt function. The (dc) mass susceptibility and magnetisation were measured in the temperature range between $100 \mathrm{~K}$ and $400 \mathrm{~K}$ and under a magnetic field between $20 \mathrm{mT}$ and $1.5 \mathrm{~T}$ using the Vibrating Sample Magnetometer (VSM). Consecutive field cooling (FC) and field heating (FH) measurements were performed on decreasing and increasing temperature, respectively. All the measurements were conducted in a step mode with a stabilised temperature at each experimental point. 


\section{Results and Discussion}

Room temperature (RT) microstructure of $0.5 \mathrm{Cr}$ and $1 \mathrm{Cr}$ alloys was examined by SEM. Representative backscattered electron images (BSE) are given in Figure 1. In accordance with this figure, $0.5 \mathrm{Cr}$ alloy (Figure 1a) appears homogenous with a single phase microstructure. Small black spots in Figure 1a are voids attributable to the casting process. On the other hand, the $1 \mathrm{Cr}$ alloy (Figure 1b) shows a dual phase, eutectic type microstructure with distinct BSE contrast between the matrix and the secondary phase. The chemical composition as verified by EDX for both alloys is given in Table 1. The average $\mathrm{Ni}_{49.6} \mathrm{Mn}_{37.3} \mathrm{Cr}_{0.7} \mathrm{Sn}_{12.4}$ chemical composition of the $0.5 \mathrm{Cr}$ alloy is found uniformly distributed within the sample and is closely related to the nominal composition. A little deviation in Mn content from nominal concentration, as frequently encountered, is ascribed to the weight loss during arc melting, due to the low vapour pressure of $\mathrm{Mn}$. The calculated $e / a$ for $0.5 \mathrm{Cr}$ is equal to 8.107. On the other hand, the chemical composition of the $1 \mathrm{Cr}$ alloy is found to be more complex. In principle, one can distinguish three different phases here in terms of composition variation. Among them, the matrix phase shows up in a light grey colour in Figure 1b, which is enriched in Sn, yet on average it internally differs in terms of $\mathrm{Cr} / \mathrm{Sn}$ ratio as follows: $\mathrm{Ni}_{52.7} \mathrm{Mn}_{31} \mathrm{Cr}_{0.7} \mathrm{Sn}_{15.6}(e / a=8.107)$, $\mathrm{Ni}_{52.1} \mathrm{Mn}_{34.3} \mathrm{Cr}_{1.3} \mathrm{Sn}_{12.3}(e / a=8.179)$. The second $\mathrm{Sn}-\mathrm{lean} \mathrm{Ni}_{63.7} \mathrm{Mn}_{31.3} \mathrm{Cr}_{2} \mathrm{Sn}_{3}$ phase gives darker BSE contrast (Figure 1b). The third phase (not shown in Figure 1b) is abundant in Ni with little Mn and Sn concentration: $\mathrm{Ni}_{90.3} \mathrm{Mn}_{8} \mathrm{Cr}_{0.2} \mathrm{Sn}_{1.5}$. For the $1 \mathrm{Cr}$ sample, one also notices more pronounced loss of $\mathrm{Mn}$ than in the case of the $0.5 \mathrm{Cr}$, due to the same reasons. On the whole, as evident from Table 1 , the $\mathrm{Cr}$ concentration in the identified phases increases with increasing $\mathrm{Ni} / \mathrm{Sn}$ ratio.
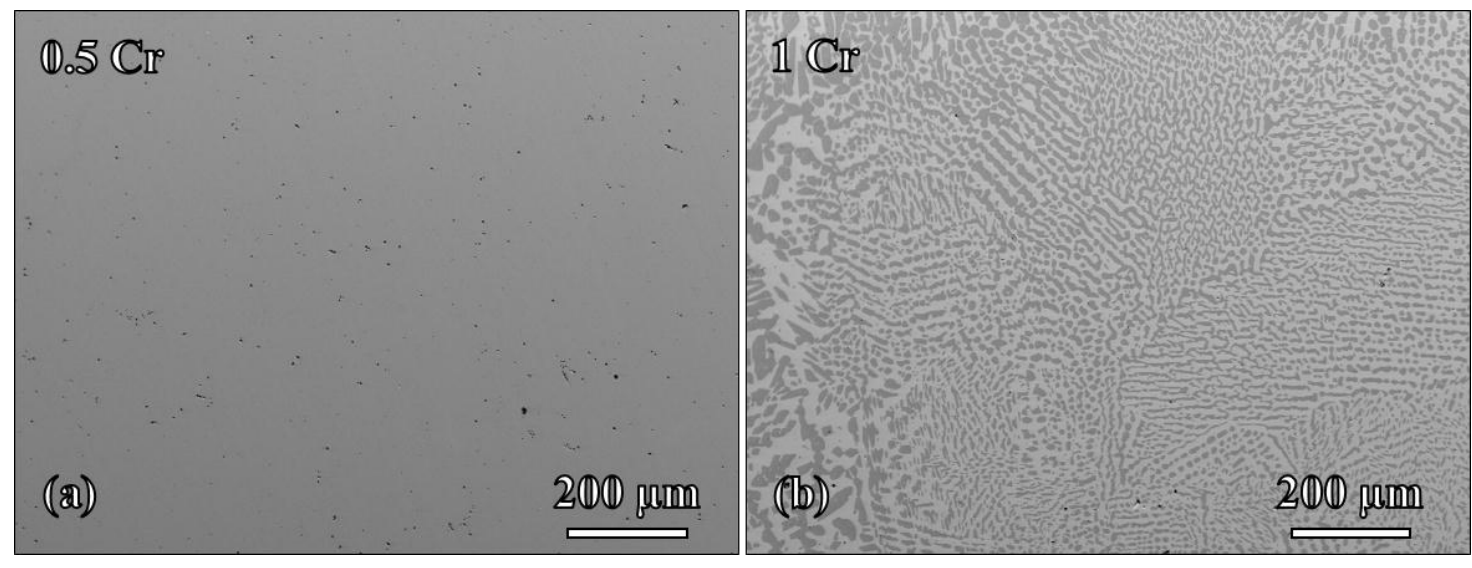

Figure 1. SEM-backscattered electron (BSE) micrographs taken from $0.5 \mathrm{Cr}$ (a) and $1 \mathrm{Cr}(\mathbf{b})$ alloys.

In order to support the preliminary SEM analysis, high energy synchrotron XRD experiments were conducted on the $0.5 \mathrm{Cr}$ and $1 \mathrm{Cr}$ samples at RT with the aim of gaining a deeper insight into the phase composition and phase structure of both alloys, owing to the superior synchrotron radiation resolution and improved grain statistics over more conventional X-ray sources. The results of theses studies in the form of integrated 2-Theta scans are presented in Figure 2. It appears that the XRD pattern taken for the $0.5 \mathrm{Cr}$ alloy (Figure 2a) shows a pronounced intensity corresponding predominantly to the austenite phase with the L2 1 Heusler structure and to martensite with the $4 \mathrm{M}$ modulated structure with a small contribution from the (111) NiMn and even lower from (200) and (210) $\mathrm{Ni}_{3} \mathrm{Mn}$. The relative phase contribution between $\mathrm{NiMn}$ and $\mathrm{Ni}_{3} \mathrm{Mn}$ is reversed in the case of the $1 \mathrm{Cr}$ alloy (Figure $2 \mathrm{~b}$ ), whose pattern can be indexed similarly according to the $\mathrm{L} 2{ }_{1}$ and $4 \mathrm{M}$ phases. In addition, it receives some contribution from the $\mathrm{Ni}_{3} \mathrm{Sn}_{2}$. Since the synchrotron measurements were performed on the bulk coarse grained samples, the Rietveld refinement was carried out on powdered samples in order to discriminate the effect of texture. The martensite phase in both samples was confirmed with 
an orthorhombic structure and Pmma space group and the lattice parameters, unit cell volume of the austenite phase and the relative volume fraction of austenite are prestented in Table 2.

Table 1. Composition and the valence electron-to-atom ratio (e/a), the forward $\left(T_{M}{ }^{A} \rightarrow{ }^{M}\right)$ and reverse $\left(T_{M}{ }^{M} \rightarrow{ }^{A}\right)$ martensitic phase transformation (MPT) temperatures, the Curie temperature of austenite $\left(T_{C}{ }^{A}\right)$, the magnetic entropy change $\left(\Delta S_{M}{ }^{m a x}\right)$ and refrigerant capacity $(R C)$ determined under the magnetic field change of $1.5 \mathrm{~T}$ for $0.5 \mathrm{Cr}$ and $1 \mathrm{Cr}$ alloys.

\begin{tabular}{|c|c|c|c|c|c|c|c|c|c|}
\hline Alloy & Composition (at.\%) & $\begin{array}{c}T_{M}^{A \rightarrow M} \\
\text { (K) }\end{array}$ & $\begin{array}{c}T_{M}^{M \rightarrow A} \\
\text { (K) }\end{array}$ & $\begin{array}{c}T_{C}{ }^{A} \\
(\mathrm{~K})\end{array}$ & $\begin{array}{c}T_{C}^{M} \\
(\mathbf{K})\end{array}$ & $\begin{array}{l}\Delta S_{M} \max \\
(\mathrm{J} / \mathrm{kg} \cdot \mathrm{K})\end{array}$ & $\begin{array}{c}R C \\
(\mathrm{~J} / \mathrm{kg})\end{array}$ & $\begin{array}{c}H L \\
(\mathrm{~J} / \mathrm{kg})\end{array}$ & $e / a$ \\
\hline $0.5 \mathrm{Cr}$ & $\mathrm{Ni}_{49.6 \pm 1} \mathrm{Mn}_{37.3 \pm 0.7} \mathrm{Cr}_{0.7 \pm 0.3} \mathrm{Sn}_{12.4 \pm 0.5}$ & 239 & 261 & 308 & 225 & 7.6 & 48.6 & 14.5 & 8.107 \\
\hline \multirow{4}{*}{$1 \mathrm{Cr}$} & $\mathrm{Ni}_{52.7 \pm 1} \mathrm{Mn}_{31 \pm 0.6} \mathrm{Cr}_{0.7 \pm 0.4} \mathrm{Sn}_{15.6 \pm 0.6}$ & 223 & 253 & 308 & - & 1.7 & 16.2 & 2.7 & 8.107 \\
\hline & $\mathrm{Ni}_{52.1 \pm 1} \mathrm{Mn}_{34.3 \pm 0.7} \mathrm{Cr}_{1.3 \pm 0.3} \mathrm{Sn}_{12.3 \pm 0.5}$ & - & - & - & - & - & - & - & 8.179 \\
\hline & $\mathrm{Ni}_{63.7 \pm 1.3} \mathrm{Mn}_{31.3 \pm 0.6} \mathrm{Cr}_{2 \pm 0.4} \mathrm{Sn}_{3 \pm 0.1}$ & - & - & - & - & - & - & - & 8.803 \\
\hline & $\mathrm{Ni}_{90.3 \pm 2} \mathrm{Mn}_{8 \pm 0.2} \mathrm{Cr}_{0.2} \mathrm{Sn}_{1.5 \pm 0.1}$ & - & - & - & - & - & - & - & 9.661 \\
\hline
\end{tabular}

Table 2. Lattice parameters for the austenite $\left(a_{c}\right)$ and martensite $\left(a_{0}, b_{0}, c_{0}\right)$ phases, unit cell volume of the austenite phase $\left(V_{c}\right)$ and the relative volume fraction (Fract $\%$ ) of the austenite phase in the $0.5 \mathrm{Cr}$ and $1 \mathrm{Cr}$ alloys.

\begin{tabular}{|c|c|c|c|c|c|c|}
\hline \multirow[t]{2}{*}{ Alloy } & \multicolumn{4}{|c|}{ Lattice Parameter ( $\AA$ ) } & \multirow[t]{2}{*}{$V_{c}\left(\AA^{3}\right)$} & \multirow[t]{2}{*}{ Fract $(\%)$} \\
\hline & $a_{c}$ & $a_{0}$ & $b_{o}$ & $c_{0}$ & & \\
\hline $0.5 \mathrm{Cr}$ & 5.9608 (6) & 8.579 (10) & $5.647(8)$ & $4.322(8)$ & $211.80(4)$ & $73(6)$ \\
\hline $1 \mathrm{Cr}$ & $5.9602(11)$ & $8.571(5)$ & $5.608(4)$ & $4.351(4)$ & $211.73(7)$ & $37(4)$ \\
\hline
\end{tabular}

It can be seen (Table 2) that the unit cell volume of the austenite phase in the $0.5 \mathrm{Cr}$ sample is slightly larger than in the $1 \mathrm{Cr}$ sample. The austenite phase is at the same time more abundant at room temperature in the $0.5 \mathrm{Cr}$ relative to the $1 \mathrm{Cr}$ sample. Overall, these results unambiguously confirm a considerable discrepancy in reference to phase composition between $0.5 \mathrm{Cr}$ and $1 \mathrm{Cr}$ alloys. This will inevitably be reflected in their thermomagnetic behaviour, discussed in the next paragraph.
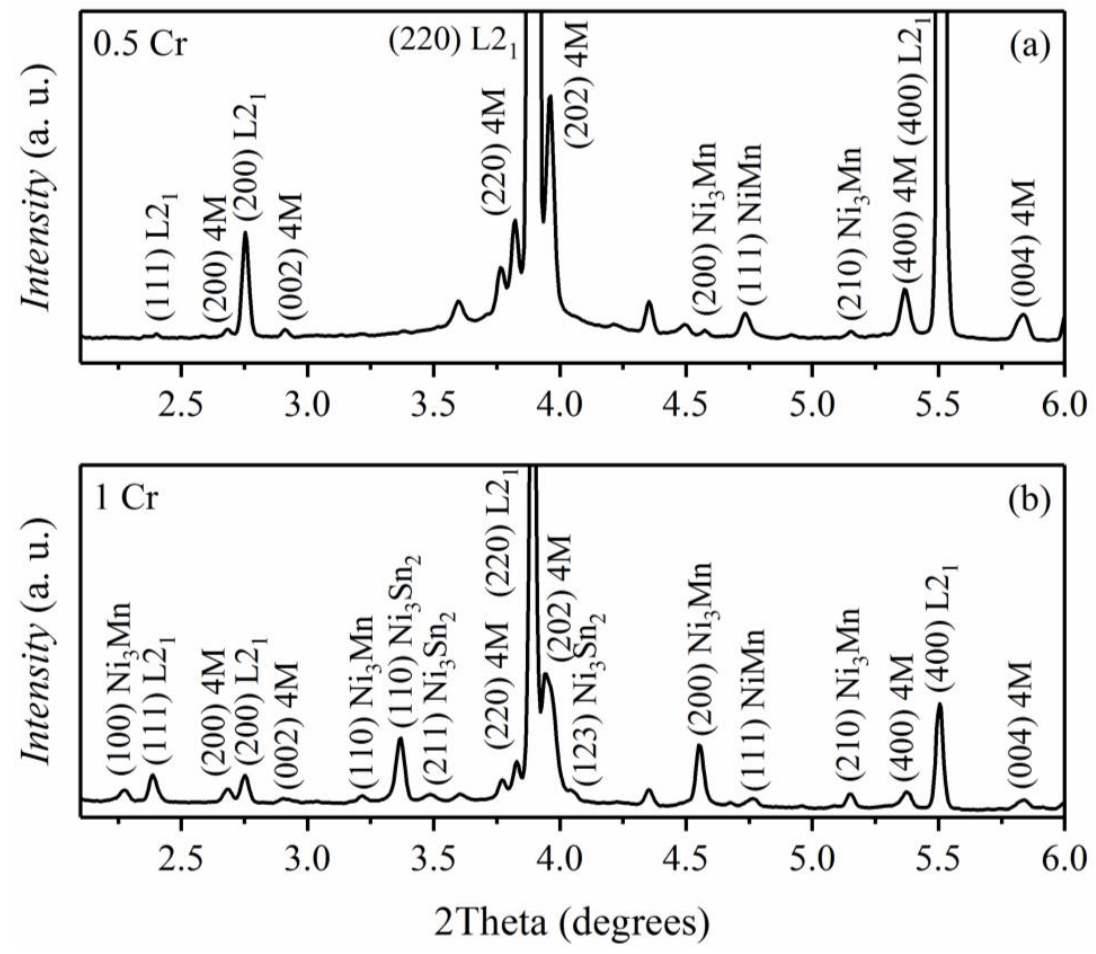

Figure 2. Integrated diffraction patterns recording the synchrotron $\mathrm{X}$-ray intensity as a function of 2-Theta angle for the $0.5 \mathrm{Cr}(\mathbf{a})$ and $1 \mathrm{Cr}(\mathbf{b})$ alloys at room temperature. 
Temperature-dependent magnetic susceptibility $(\chi)$ and magnetisation $(M)$ for the $0.5 \mathrm{Cr}$ and $1 \mathrm{Cr}$ alloys under the magnetic field of $2 \mathrm{mT}$ (Figure $3 \mathrm{a}$ ) and $1 \mathrm{~T}$ (Figure $3 \mathrm{~b}$ ) were recorded in the FC and FH mode within the 100-400 K temperature range. On cooling (Figure 3a) from around $400 \mathrm{~K}$, both alloys first showed a near-zero $\chi$ indicating paramagnetic state, then around $308 \mathrm{~K}$, magnetic susceptibility increases marking the $T_{C}{ }^{A}$. It then drops again at around $T_{M}$ with a characteristic hysteretic splitting between the FC and FH modes, which is a fingerprint of the first order nature MPT. At the lower temperature, $\chi$ begins to increase, since upon further cooling the system goes through the Curie temperature of the martensite phase $\left(T_{C}{ }^{M}\right)$, however in the case of the $0.5 \mathrm{Cr}$ alloy the low temperature $\chi$ remains well below the values observed for the austenite within the $T_{M} \leq T \leq T_{C}{ }^{A}$ range. The characteristic forward $\left(T_{M}{ }^{A} \rightarrow^{M}\right)$ and reverse $\left(T_{M}{ }^{M} \rightarrow^{A}\right)$ MPT temperatures, as well as the $T_{C}{ }^{A}$ and $T_{C}{ }^{M}$ temperatures, have been determined from the corresponding inflection points on the FC and FH cures, respectively. They are collated in Table 1. From the comparison between the thermomagnetic behavior of the $0.5 \mathrm{Cr}$ and $1 \mathrm{Cr}$ alloys, it is to be noted that the $T_{M}{ }^{A} \rightarrow^{M}(239 \mathrm{~K})$ of the former is $16 \mathrm{~K}$ above the $T_{M}{ }^{A} \rightarrow^{M}(223 \mathrm{~K})$ of the latter. On the contrary, the transformation temperature range given as $\Delta T_{h}=T_{M}{ }^{A} \rightarrow^{M}-T_{M}{ }^{M} \rightarrow^{A}$ for $1 \mathrm{Cr}(30 \mathrm{~K})$ alloy exceeds by $7 \mathrm{~K}$ the $\Delta T_{h}$ observed for the $0.5 \mathrm{Cr}$ sample $(23 \mathrm{~K})$. This fact also manifests itself well in Figure $3 \mathrm{a}$ by a relatively broad FC-FH hysteresis noticeable for the $1 \mathrm{Cr}$ alloy. The magnetic transition temperatures show good agreement with the respective temperatures determined according to the Curie-Weiss Law $\chi(T)=C /\left(T-\theta_{C W}\right)$, where $C$ is the Curie constant and $\theta_{\mathrm{CW}}$ is the Curie-Weiss constant. The determined $1 / \chi$ dependence (FC) is portrayed for both the $0.5 \mathrm{Cr}\left(\theta_{\mathrm{CW}}=312 \mathrm{~K}\right)$ and $1 \mathrm{Cr}\left(\theta_{\mathrm{CW}}=309 \mathrm{~K}\right)$ alloys near $T_{\mathrm{C}}{ }^{A}$ in the inset in Figure 3a. The steeper slope of the $1 / \chi$ vs. $T$ curve (inset Figure $3 a$ ) noted for the $1 \mathrm{Cr}$ alloy relative to the $0.5 \mathrm{Cr}$ indicates the difference in the effective magnetic moment $(\bar{\mu})$ between both alloys above $300 \mathrm{~K}$. From the linear fits, the $\bar{\mu}$ in the paramagnetic state of either phase can be determined according to:

$$
\bar{\mu}=\sqrt{\frac{3 M k_{B}}{\mu_{0} N_{A} b_{\text {mass }}}},
$$

where $M$ is the molecular mass, $k_{B}$ Boltzmann's constant, $\mu_{0}$ is the permeability of the vacuum, $N_{A}$ Avogadro's number and $b_{\text {mass }}$ is the slope of the linear fit determined for both alloys within the $336 \mathrm{~K}$ and $400 \mathrm{~K}$ temperature range. The $\bar{\mu}$ for the $0.5 \mathrm{Cr}$ alloys is equal to $2.8 \mu_{\mathrm{B}}\left(\bar{\mu}_{M n}=7.6 \mu_{\mathrm{B}}\right)$, whereas

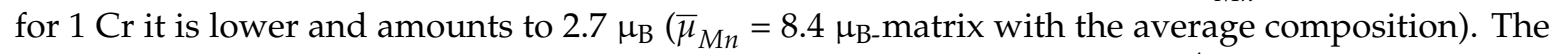
disparity in the magnetic susceptibility below $300 \mathrm{~K}$ within the $T_{M} \leq T \leq T_{C}{ }^{A}$ temperature range for both alloys is also seen from the relative positions of the $\chi$ vs. $T$ and $M$ vs. $T$ (Figure 3a,b). At the lower temperature below $T_{C}{ }^{M}$ the $\mathrm{FC}$, and $\mathrm{FH}$ curves for the $0.5 \mathrm{Cr}$ under $20 \mathrm{mT}$ continue to rise above the corresponding curves recorded for the $1 \mathrm{Cr}$ alloy, whereas at $1 \mathrm{~T}$ all curves merge. Interestingly, a small hysteresis appears within the $175-200 \mathrm{~K}$ range for $1 \mathrm{Cr}$ at both $20 \mathrm{mT}$ and $1 \mathrm{~T}$, which may either be linked to some fraction of the austenite phase transforming directly to ferromagnetic rather than weakly magnetic martensite, since $T<T_{C}{ }^{M}$, or alternatively this may be associated with a smeared Curie temperature or $T_{M}$ due to the complex chemical composition, e.g., second MPT or intermartensitic transformation may be more plausible due to the presence of hysteresis. In fact, the inflection point $\left(\frac{d \chi}{d T}<0\right)$ found on the $\mathrm{FH}$ curve for this temperature range is equal to $195 \mathrm{~K}$, whereas that for the FC curve amounts to $180 \mathrm{~K}$, which is a difference of $15 \mathrm{~K}$; for this reason, it is difficult to reconcile with the second order nature magnetic transition (inset in Figure $3 \mathrm{~b}-\mathrm{d} M_{(\mathrm{FC}, \mathrm{FH})} / \mathrm{d} T$ vs. $T$ at $1 \mathrm{~T}$ ). A similar effect for the same alloy is noted around the $T_{C}{ }^{A}$, where the temperatures determined from the FH $(316 \mathrm{~K})$ and FC $(309 \mathrm{~K})$ curves stray by $7 \mathrm{~K}$. Higher magnetic field $(2 \mathrm{~T})$ has almost null effect on the forward and reverse $T_{M}$ in both alloys $\left(0.5 \mathrm{Cr}\right.$ at $2 \mathrm{~T}: T_{M}{ }^{A \rightarrow M}=236 \mathrm{~K}, T_{M}{ }^{M \rightarrow A}=260 \mathrm{~K}$; $1 \mathrm{Cr}$ at $2 \mathrm{~T}: T_{M}{ }^{A \rightarrow M}=223 \mathrm{~K}, T_{M}{ }^{M \rightarrow A}=250 \mathrm{~K}$ ).

More detailed evaluation of magnetisation $(\mathrm{FH})$ as a function of the magnetic field at selected temperatures within the $100-400 \mathrm{~K}$ range for the $0.5 \mathrm{Cr}$ and $1 \mathrm{Cr}$ alloys is given in Figure 4 . Consistent with Figure 3, the magnetisation of the $0.5 \mathrm{Cr}$ (Figure $4 \mathrm{a}$ ) at $100 \mathrm{~K}$, the temperature at which martensite is expected to be in the stable phase, reaches $\sim 28.7 \mathrm{~A} \cdot \mathrm{m}^{2} \cdot \mathrm{kg}^{-1}$. The coercive field, following FC under 
$\mu_{0} \cdot \Delta H=1 \mathrm{~T}$, at this temperature is equal to $H_{C}=\left|H_{1}-H_{2}\right| / 2=338$ Oe and simultaneously there is almost null exchange bias field $H_{E}=-\left(H_{1}+H_{2}\right) / 2=-1 \mathrm{Oe}$, where $H_{1}$ and $H_{2}$ denote the left and right coercive fields at zero magnetization. The magnetisation then gradually decreases with increasing temperature $(\mathrm{FH})$ as the system approaches the $T_{C}{ }^{M}$ followed by the $T_{M}$. Subsequently, at $262 \mathrm{~K}$, just above $T_{M}{ }^{A} \rightarrow^{M}, M$ assumes the value of $\sim 40.9 \mathrm{~A} \cdot \mathrm{m}^{2} \cdot \mathrm{kg}^{-1}$, which is the highest in the investigated temperature range and is $12.2 \mathrm{~A} \cdot \mathrm{m}^{2} \cdot \mathrm{kg}^{-1}$ above the magnetisation of martensite at $100 \mathrm{~K}$. Further increase of the temperature brings the magnetisation down to the lowest of $1.8 \mathrm{~A} \cdot \mathrm{m}^{2} \cdot \mathrm{kg}^{-1}$ at $400 \mathrm{~K}$ as the austenite phase becomes paramagnetic. On the other hand, for the $1 \mathrm{Cr}$ alloy, the maximum magnetisation of $28 \mathrm{~A} \cdot \mathrm{m}^{2} \cdot \mathrm{kg}^{-1}$ under $\mu_{0} \cdot \Delta H=1 \mathrm{~T}$ is reached at $100 \mathrm{~K}$ for the martensite state, and the $M$ value is comparable with the $0.5 \mathrm{Cr}$ under the same conditions. After FC under the constant field $(1 \mathrm{~T}), H_{E}=11.5 \mathrm{Oe}$ and $H_{C}=520 \mathrm{Oe}$ at $78 \mathrm{~K}$. Continued $\mathrm{FH}$ results in magnetization collapse, which settles at $18 \mathrm{~A} \cdot \mathrm{m}^{2} \cdot \mathrm{kg}^{-1}$ at $254 \mathrm{~K}$, just above the $T_{\mathrm{M}}{ }^{M} \rightarrow^{A}$, and then higher up with temperature (276 K) at $21.4 \mathrm{~A} \cdot \mathrm{m}^{2} \cdot \mathrm{kg}^{-1}$. Eventually, $M$ comes down to $12.4 \mathrm{~A} \cdot \mathrm{m}^{2} \cdot \mathrm{kg}^{-1}(312 \mathrm{~K})$ and finally $2.3 \mathrm{~A} \cdot \mathrm{m}^{2} \cdot \mathrm{kg}^{-1}$ $(370 \mathrm{~K})$, as the system goes well above the $T_{\mathrm{C}}{ }^{A}$.
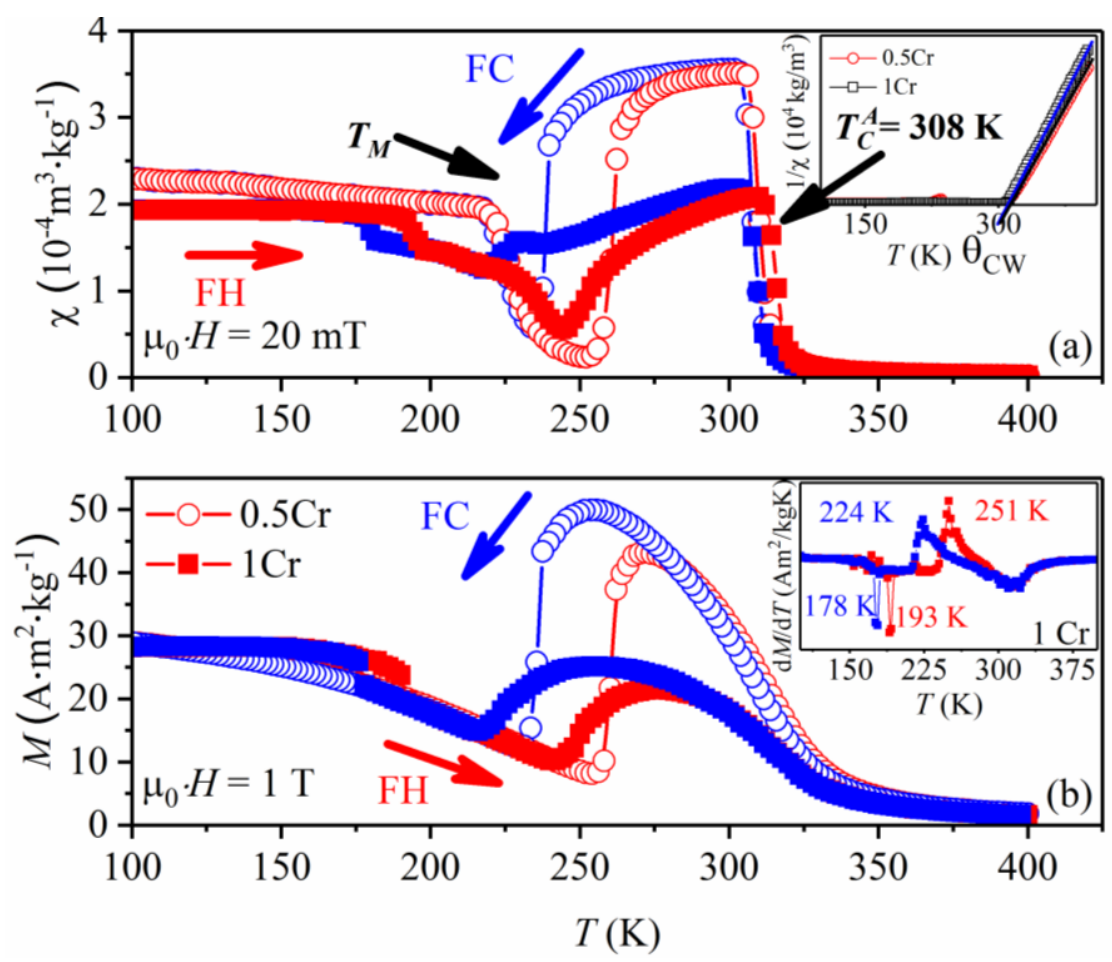

Figure 3. Temperature dependence of magnetic susceptibility $(\chi)$ and magnetisation $(M)$ under a magnetic field of $20 \mathrm{mT}(\mathbf{a})$ and $1 \mathrm{~T}$ (b) on cooling (FC) and on heating (FH) for the $0.5 \mathrm{Cr}$ and $1 \mathrm{Cr}$ alloys. The inset in Figure 3a shows the reciprocal of the magnetic susceptibility vs. temperature for the $0.5 \mathrm{Cr}$ and $1 \mathrm{Cr}$ alloys, whereas the inset in Figure $3 \mathrm{~b}$ shows the $\mathrm{d} M / \mathrm{d} T$ (FC—red, FH—blue) vs. temperature for the $1 \mathrm{Cr}$ sample. 

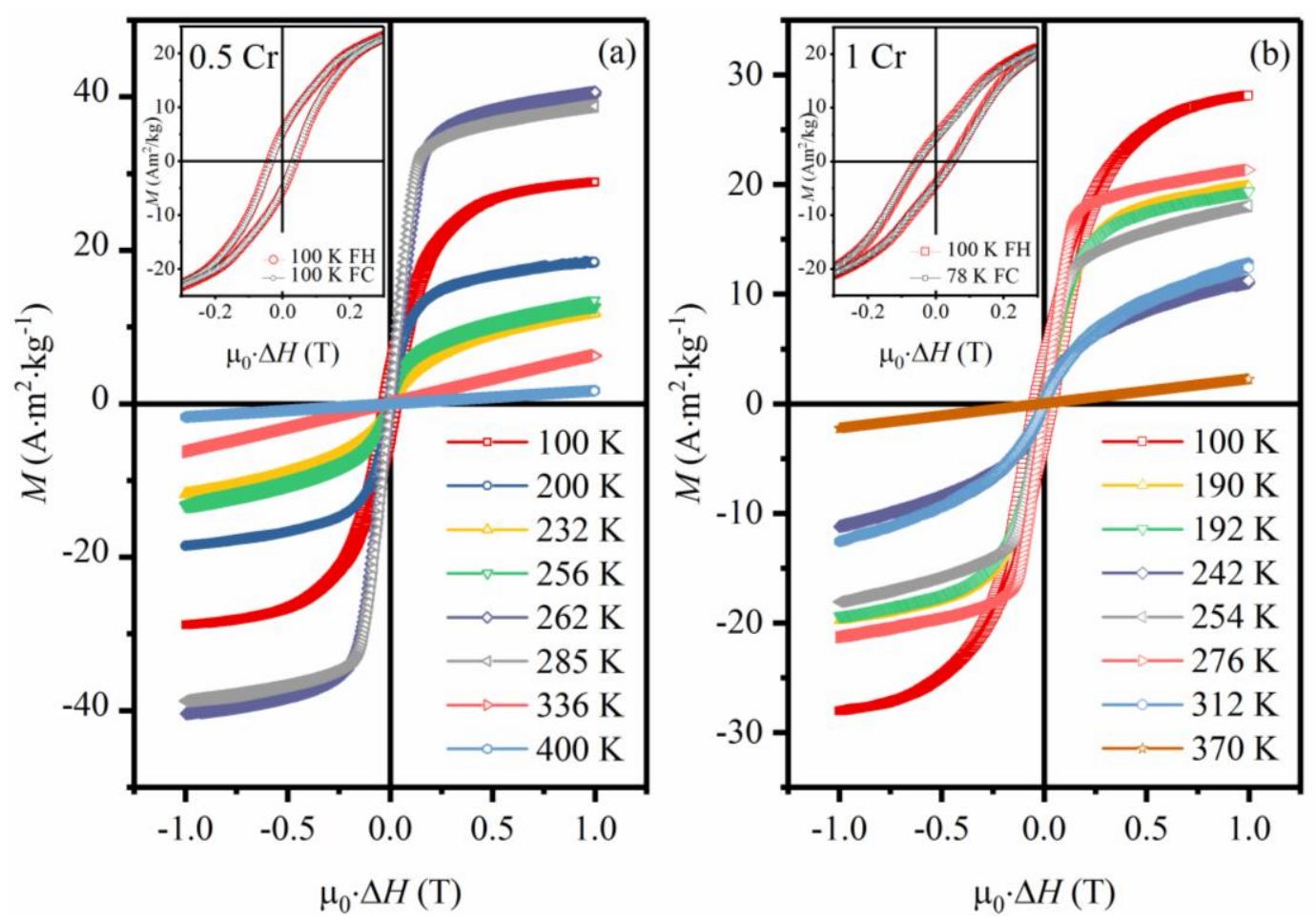

Figure 4. Isothermal magnetisation curves for the $0.5 \mathrm{Cr}(\mathbf{a})$ and $1 \mathrm{Cr}(\mathbf{b})$ alloys in the temperature range between 100 and $400 \mathrm{~K}$.

The magnetisation difference between martensite and austenite around $T_{M}$ is well manifested in Figure 5, which shows isothermal magnetisation curves $M(H)$ for the $0.5 \mathrm{Cr}$ and $1 \mathrm{Cr}$ alloys across the MPT temperature range. The curves were measured by first cooling each sample to $150 \mathrm{~K}$ followed by $10 \mathrm{~min}$ isothermal pause, then the temperature was increased to the desired measuring temperature and the sample was again left for $10 \mathrm{~min}$ to stabilise. The $M(H)$ isotherm was then recorded and the sample was subsequently cooled down to $150 \mathrm{~K}$, where the cycle was repeated. The measurements revealed typical metamagnetic behaviour, which is clearly evidenced by Figure $5 a, c$, i.e., $M$ increases with increasing $\mu_{0} \cdot \Delta H$ signifying the magnetic field induced reverse MPT. The corresponding Arrott plots for the $0.5 \mathrm{Cr}$ (Figure $5 \mathrm{~b}$ ) and $1 \mathrm{Cr}$ (Figure $5 \mathrm{~d}$ ) confirm the first order nature of the transformation, what is reflected in the S-shape like $M^{2}$ vs. $H / M$ curves around $T_{M}$. The transformation hysteresis between field up and field down $M(H)$ curves is highlighted with a light blue colour for both the $0.5 \mathrm{Cr}$ and $1 \mathrm{Cr}$ alloys and the computed hysteresis loss $(H L)$ vs. $T$ dependencies for both alloys are given in the insets in Figure 6. The $\Delta M$ for the $0.5 \mathrm{Cr}$ alloy is $33.6 \mathrm{~A} \cdot \mathrm{m}^{2} \cdot \mathrm{kg}^{-1}$ within the $252-272 \mathrm{~K}$ $(\Delta T=20 \mathrm{~K})$ transition range, whereas that for the $1 \mathrm{Cr}$ alloy is $10.1 \mathrm{~A} \cdot \mathrm{m}^{2} \cdot \mathrm{kg}^{-1}$ within the broader $232-276 \mathrm{~K}(\Delta T=44 \mathrm{~K})$. 

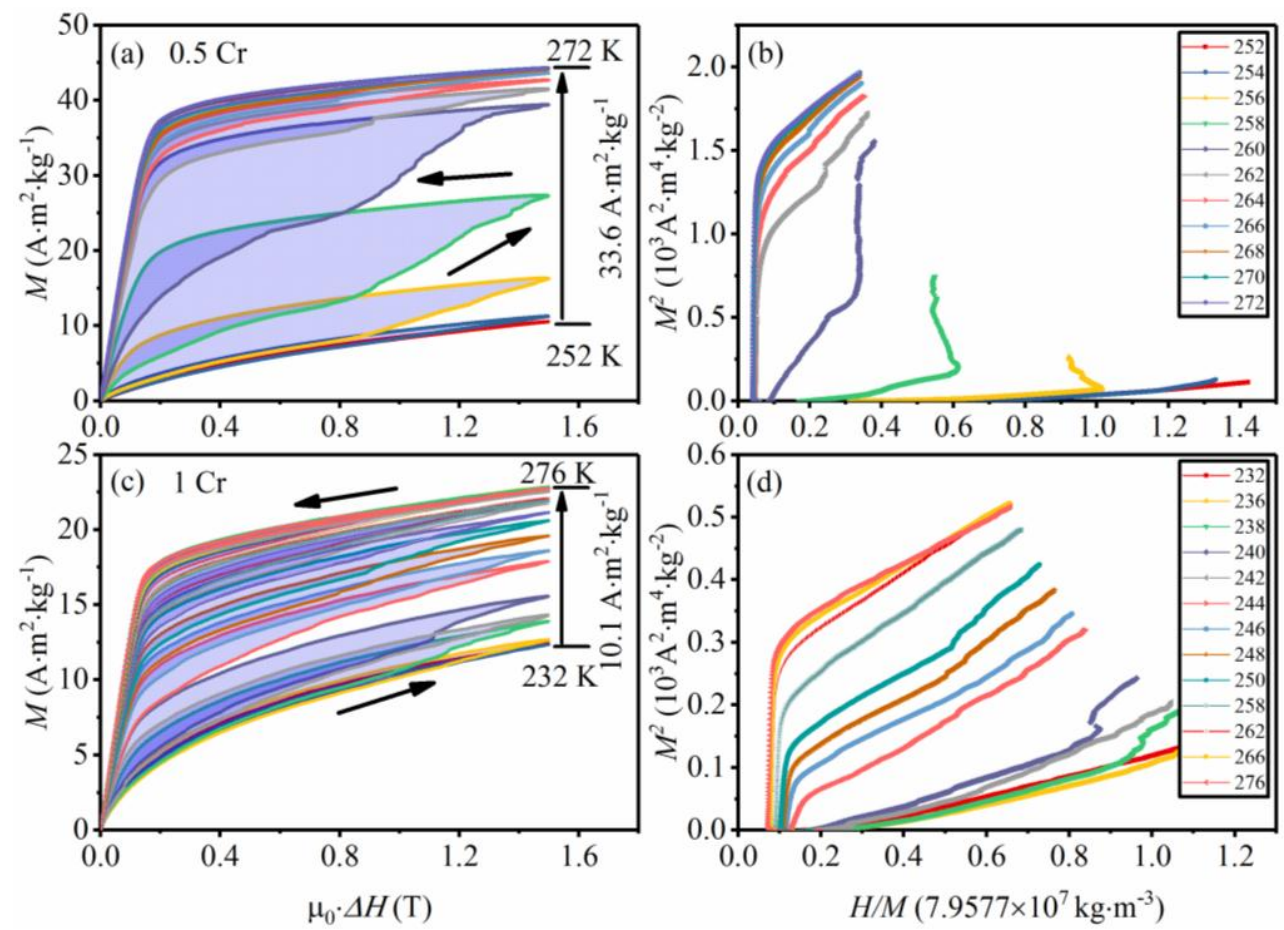

Figure 5. Isothermal magnetisation curves in the area of $T_{M}$ and corresponding Arrott plots for the $0.5 \mathrm{Cr}(\mathbf{a}),(\mathbf{b})$ and $1 \mathrm{Cr}(\mathbf{c}),(\mathbf{d})$ alloys.
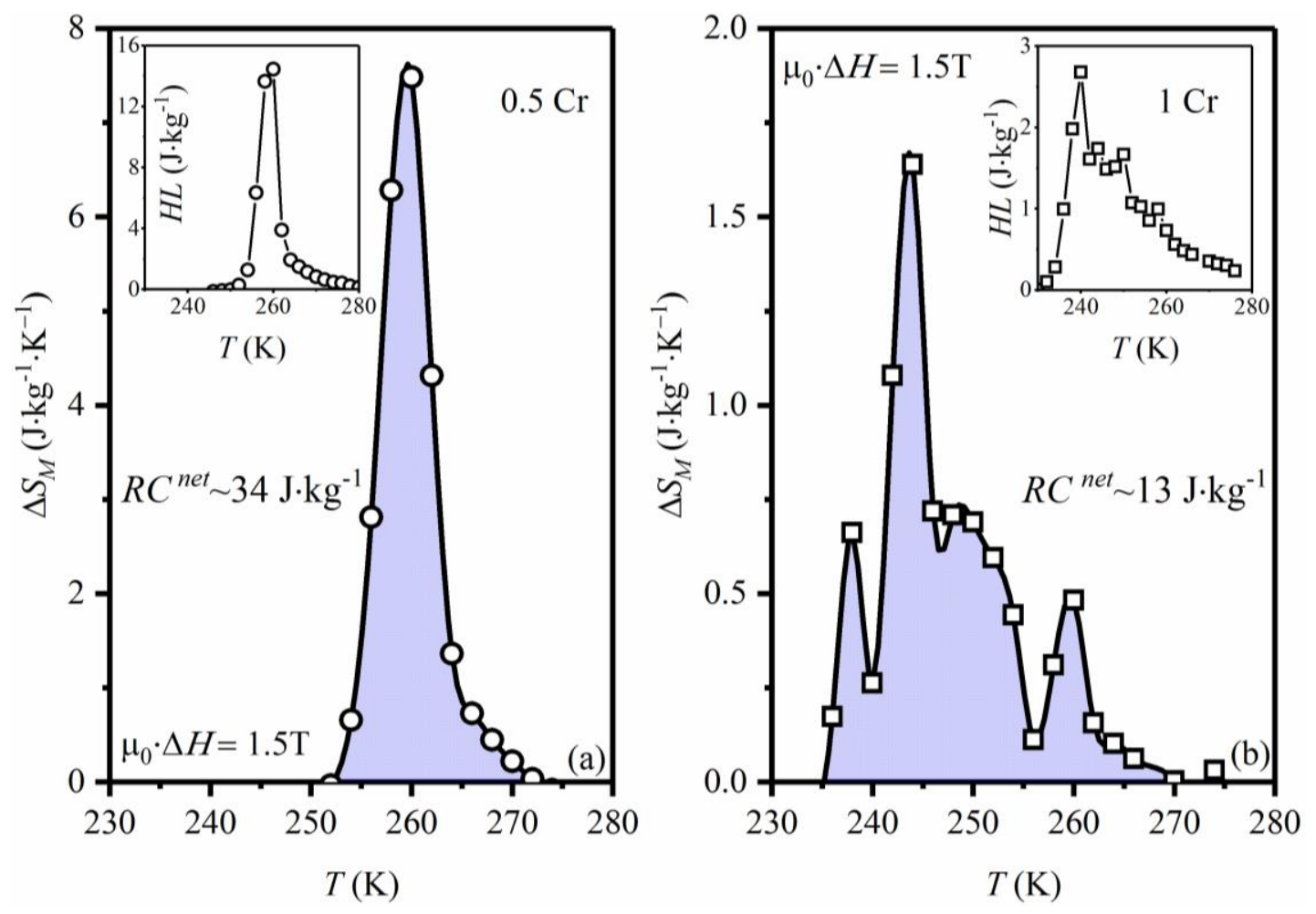

Figure 6. Temperature dependence of magnetically induced $\Delta S_{M}$ in the magnetic field of $1.5 \mathrm{~T}$ for the $0.5 \mathrm{Cr}(\mathbf{a})$ and $1 \mathrm{Cr}(\mathbf{b})$. Insets show the corresponding hysteresis loss $(H L)$ related to the first order nature of MPT.

Based on the isothermal $M(H)$ curves, the magnetic entropy change $\left(\Delta S_{M}\right)$ has been computed employing the Maxwell relation: 


$$
\Delta S_{M}=\mu_{0} \int_{0}^{H_{m}}\left(\frac{\partial M(H, T)}{\partial T}\right)_{H} d H
$$

The temperature dependence of the $\Delta S_{M}$ in the magnetic field of $\mu_{0} \cdot \Delta H=1.5 \mathrm{~T}$ for both the $0.5 \mathrm{Cr}$ and $1 \mathrm{Cr}$ alloys is given in Figure 6. The maximum $\Delta S_{M}{ }^{\max }$ for the $0.5 \mathrm{Cr}$ sample peaks at $260 \mathrm{~K}$ with $7.5 \mathrm{~J} / \mathrm{kg} \cdot \mathrm{K}$. The $H L$ (inset Figure $6 \mathrm{a}$ ) has been computed as:

$$
H L\left(T, H_{m}\right)=-\mu_{0}\left(\int_{H_{m}}^{0} M(T, H) d H+\int_{0}^{H_{m}} M(T, H) d H\right)
$$

The maximum $H L$ under $\mu_{0} \cdot \Delta H=1.5 \mathrm{~T}$ at $260 \mathrm{~K}$ is equal to $14.5 \mathrm{~J} / \mathrm{kg}$. In order to compute the $R C$, the area under the $\Delta S_{M}$ peak has been integrated and yielded $48.6 \mathrm{~J} / \mathrm{kg} \cdot \mathrm{K}$, which after subtraction of $H L$ gives the effective $R C^{\text {net }}$ of around $34 \mathrm{~J} / \mathrm{kg}$ under $\mu_{0} \cdot \Delta H=1.5 \mathrm{~T}$. In the case of the $1 \mathrm{Cr}$ sample, the maximum $\Delta S_{M}{ }^{\max }$ of $1.6 \mathrm{~J} / \mathrm{kg} \cdot \mathrm{K}$ was determined at $244 \mathrm{~K}$. The $H L$ was estimated at $2.7 \mathrm{~J} / \mathrm{kg}$, whereas the peak area adds up to $16.2 \mathrm{~J} / \mathrm{kg}$, which gives $R C^{\text {net }}$ of $13 \mathrm{~J} / \mathrm{kg}$. It is worth noting that the $\Delta S_{M}$ computed for the $1 \mathrm{Cr}$ alloy is composed of four peaks and overall spreads over a broader temperature range, unlike the single peaked $\Delta S_{M}{ }^{\max }$ for the $0.5 \mathrm{Cr}$ alloy.

The comparison between $\Delta S_{M}{ }^{\max }$ and $R C$ for both the $0.5 \mathrm{Cr}$ and $1 \mathrm{Cr}$ alloys as a function of the magnetic field change is given in Figure 7. Both parameters increase with increasing magnetic field intensity to up $1.5 \mathrm{~T}$. The $R C$ shows a linear dependence on the $\mu_{0} \cdot \Delta H$ (Figure $7 \mathrm{~b}$ ), whereas the $\Delta S_{M}{ }^{m a x}$ also initially increases linearly to around $1 \mathrm{~T}$, then deviates from linear behaviour (Figure 7a). The magnitude of the $\Delta S_{M}{ }^{m a x}$ determined for the $0.5 \mathrm{Cr}$ is nearly five times larger than the $\Delta S_{M}$ max value obtained for the $1 \mathrm{Cr}$ alloy. The $R C$ shown by the $0.5 \mathrm{Cr}$ is three times the $R C$ obtained with the $1 \mathrm{Cr}$. The inset in Figure 7a illustrates the dependence of the $\Delta S_{M}{ }^{\max }$ on $e / a$ (literature values $[3,13,26]$ ) under $\mu_{0} \cdot \Delta H=1 \mathrm{~T}$ for various Ni-Mn-Sn alloys, whose composition was modified by varying $\mathrm{Ni} / \mathrm{Mn}$ and $\mathrm{Mn} / \mathrm{Sn}$ ratio ( $\mathrm{Mn} \geq 37$ at.\%). The result determined for the $0.5 \mathrm{Cr}$ alloy is also plotted for reference. It is seen from the inset that the $\Delta S_{M}{ }^{m a x}$ progressively decreases with increasing $e / a$, which can be understood in relation to the $T_{M}$ and $T_{C}{ }^{A}$ dependence on the $e / a$.
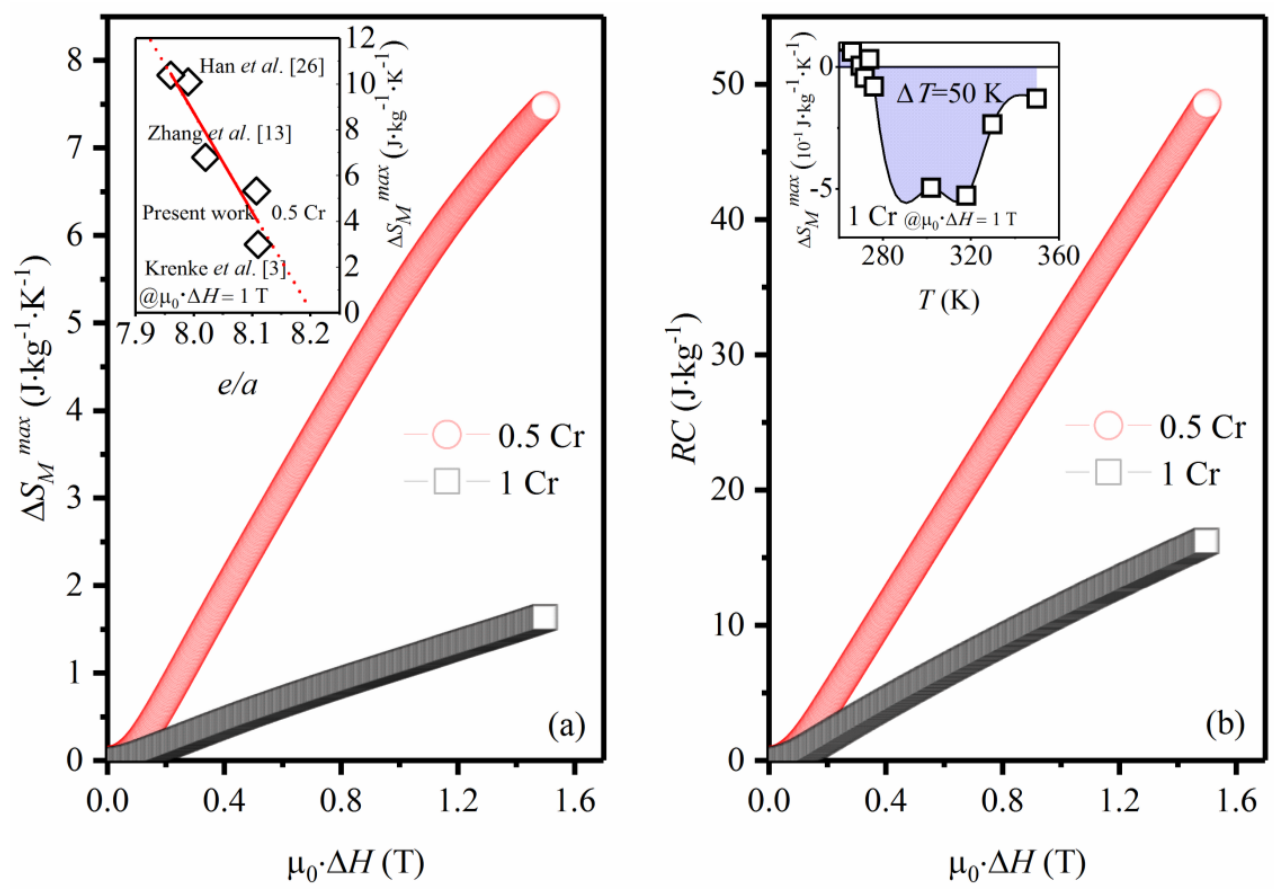

Figure 7. Magnetic field dependence of $\Delta S_{M}{ }^{m a x}$ and of calculated $R C$ for the $0.5 \mathrm{Cr}$ (a) and $1 \mathrm{Cr}$ (b) alloys. Inset (a) shows $\Delta S_{M}{ }^{\max }$ vs. e/a for selected Ni-Mn-Sn alloys and presently studied $0.5 \mathrm{Cr}$ alloy. Inset (b) gives $\Delta S_{M}{ }^{\max }$ vs. $T$ dependence around $T_{C}{ }^{A}$ for the $1 \mathrm{Cr}$ sample. 
On the whole, it is shown that the studied $0.5 \mathrm{Cr}$ and $1 \mathrm{Cr}$ alloys demonstrate significant differences in terms of their thermomagnetic behaviour and accompanying $\Delta S_{M}$ vs. temperature dependencies, which result from the changes in composition and the microstructure. On average, the $0.5 \mathrm{Cr}$ alloy is identified with the single $\mathrm{Ni}_{49.6} \mathrm{Mn}_{37.3} \mathrm{Cr}_{0.7} \mathrm{Sn}_{12.4}$ phase $(e / a=8.107)$, whereas the $1 \mathrm{Cr}$ alloy displays a multiphase microstructure with the dominant matrix of average $\mathrm{Ni}_{52.4} \mathrm{Mn}_{32.7} \mathrm{Cr}_{1} \mathrm{Sn}_{14}$ composition $(e / a=8.146)$. The $0.5 \mathrm{Cr}$ alloy undergoes MPT at a higher temperature $\left(T_{M}{ }^{A} \rightarrow{ }^{M}=239 \mathrm{~K}\right)$ relative to the $1 \mathrm{Cr}$ alloy $\left(T_{M}{ }^{A} \rightarrow^{M}=223 \mathrm{~K}\right)$ despite the lower $e / a$ ratio (Figure 3). This finding resonates with experimentally established evidence that Mn-rich Heusler systems do not always conform to the $e / a$ vs. $T_{M}$ dependence [11,18]. Alternatively, the decrease in $T_{M}$ might be justified by the weakening in hybridization states between $\mathrm{Ni}$ and $\mathrm{Mn}$ stemming from the lower Mn content in the $1 \mathrm{Cr}$ alloy. This fits with the fact that $T_{M}$ in Mn-rich Heusler alloys appears to suffer from Ni or Mn depletion, which points to the role of the extent of hybridization between the Ni $3 \mathrm{~d}$ states and the $3 \mathrm{~d}$ states of the excess $\mathrm{Mn}$ atoms at $\mathrm{Sn}$ sites $\left(\mathrm{Mn}_{\mathrm{Sn}}\right)$ in driving the transition $[11,27,28]$. In the present study, consistent with experimental findings, $T_{M}$ is found to decrease with increased $\mathrm{Ni} / \mathrm{Mn}$ ratio; the $\mathrm{Ni} / \mathrm{Mn}$ for the $0.5 \mathrm{Cr}$ is determined at 1.3, whereas that for $1 \mathrm{Cr}$ is equal to 1.6. The average matrix composition of the $1 \mathrm{Cr}$ alloy is therefore nearer to the stoichiometric $\mathrm{Ni}_{2} \mathrm{MnSn}$ than the $0.5 \mathrm{Cr}$ and, at stoichiometric composition, Ni-Mn-Sn does not undergo MPT [29]. The stronger hybridization between $\mathrm{Ni}$ and $\mathrm{Mn}$ in the $1 \mathrm{Cr}$ alloy might therefore in this light account for the strengthened covalent bond and, thus, a more stable $\mathrm{L} 2{ }_{1}$ structure with lower $T_{M}$.

The Curie temperature for both alloys is found to be equal to $308 \mathrm{~K}$, which confirms its poor sensitivity to composition change. The lower magnetisation of the $1 \mathrm{Cr}$ alloy across the MPT compared to the $0.5 \mathrm{Cr}$ alloy may be related to the lower fraction of ferromagnetic austenite undergoing the MPT in the former, which also accounts for the lower $\Delta M$ (Figures 4 and 5). Another factor reducing the ferromagnetic exchange in the austenite phase and, thus, $\Delta M$ is the smaller contribution of $\mathrm{Mn}$ to the net magnetic moment due to diminished Mn concentration in the $1 \mathrm{Cr}$ specimen; it is well established that the magnetic moment in $\mathrm{Ni}-\mathrm{Mn}$-based systems is chiefly confined to $\mathrm{Mn}$ atoms [30]. On the contrary, the similar level of magnetisation between the samples at the lowest temperatures $(100 \mathrm{~K})$ may result from the stronger antiferromagnetic (AFM) exchange, typically setting in below 100 $\mathrm{K}$ in Mn-rich alloys [6,31] and, in this instance, also nurtured by higher Mn content in the $0.5 \mathrm{Cr}$ : i.e., $\mathrm{Mn}_{\mathrm{Sn}}$ antisites giving rise to stronger AFM coupling [32]. Hence, although the martensite fraction is limited in the $1 \mathrm{Cr}$ alloy, it nonetheless shows similarity to the $0.5 \mathrm{Cr}$ ferromagnetic exchange, since more enhanced AFM exchange in the $0.5 \mathrm{Cr}$ compromises the ferromagnetic interaction and in this way compensates for the lower martensite fraction in the $1 \mathrm{Cr}$ sample.

Although the $\Delta M$ within the MPT transition range is smaller in the $1 \mathrm{Cr}$ alloy than in the $0.5 \mathrm{Cr}$, the MPT in the $1 \mathrm{Cr}$ sample occurs over a broader temperature range, which is then mirrored in the more widespread temperature dependence of the $\Delta S_{M}$ (Figure 6). The multi-peak shape of the $\Delta S_{M}$ vs. $T$ curve in the $1 \mathrm{Cr}$ alloy, unlike in the case of $0.5 \mathrm{Cr}$, may suggest multistep transformation spurred on by smeared composition. This would then also justify the observed temperature hysteresis between the FC and FH curves around the $T_{C}{ }^{A}$ and well below the $T_{M}$ in the case of the $1 \mathrm{Cr}$ alloy (Figure 3) [33]. The HL under the action of a magnetic field is simultaneously reduced in the $1 \mathrm{Cr}$ due to the smaller fraction of the transforming martensite phase at each given temperature within the MPT temperature range (Figure 5). Even if the $\Delta S_{M}$ in the case of the $1 \mathrm{Cr}$ alloy shows extended temperature dependence, the maximum $\Delta S_{M}$ value obtainable is lower than with the $0.5 \mathrm{Cr}$. This is ascribed to the lower $\Delta M$ across the MPT and since, according to the Clausius-Clapeyron (magnetic) relation the change in the $\Delta S_{M}$ in response to the change in the magnetic field is given by $\Delta S / \Delta M=\mu_{0} \Delta H / \Delta T_{M}$, with decreasing $\Delta M$ the $\Delta S_{M}$ accordingly decreases. Lower $\Delta S_{M}$ in the $1 \mathrm{Cr}$ results in the lower net $R C$, regardless of the fact that it spreads over a broader temperature interval. This demonstrates that effective MCE engineering is based on a subtle balance between the magnitude of the $\Delta S_{M}$ and its temperature dependence, with the avoidance of a significant compromise of one at the expense of another. 
These results fall in line with recent literature reports on Ni-Mn-Sn systems and it is shown that, in general, the $\Delta S_{M}$ decreases with increasing $e / a$ (inset Figure 7a). It again can be traced to the diminishing $\Delta M$ due to the increasing contribution of the paramagnetic state on both sides of the transformation, since in general the $T=T_{C}{ }^{A}-T_{M}$ temperature decreases with increasing $e / a$ [10]. It is also worth pointing out the relatively broad temperature span accompanying the direct MCE around the $T_{C}{ }^{A}$ (inset Figure $7 \mathrm{~b}$ ). However limited the second order, magnetic transformation takes place over a wide temperature window $\sim 50 \mathrm{~K}$, which, provided that the $\Delta S_{M}(<0)$ was enhanced, could potentially increase the effective $R C$, beneficial for the total MCE response.

\section{Conclusions}

Phase composition and thermomagnetic behavior of two Ni-Mn-Sn alloys substituted with 0.5 and 1 at.\% $\mathrm{Cr}$ for $\mathrm{Mn}$ have been studied. The alloy substituted with lower $\mathrm{Cr}$ concentration shows the average composition of $\mathrm{Ni}_{49.6} \mathrm{Mn}_{37.3} \mathrm{Cr}_{0.7} \mathrm{Sn}_{12.4}(\mathrm{e} / \mathrm{a}=8.107)$, whereas that with higher $\mathrm{Cr}$ content has a multiphase microstructure with the matrix phase of average $\mathrm{Ni}_{52.4} \mathrm{Mn}_{32.7} \mathrm{Cr}_{1} \mathrm{Sn}_{14}$ stoichiometry $(e / a=8.146)$. The $\mathrm{Ni}_{49.6} \mathrm{Mn}_{37.3} \mathrm{Cr}_{0.7} \mathrm{Sn}_{12.4}$ alloy undergoes MPT at $239 \mathrm{~K}$ and under the magnetic field change of $\mu_{0} \cdot \Delta H=1.5$ T yields $\Delta S_{M}{ }^{m a x}=7.6 \mathrm{~J} / \mathrm{kg} \cdot \mathrm{K}$. This produces the $R C$ on the order of $48.6 \mathrm{~J} / \mathrm{kg}$, reduced by $29.8 \%$ due to hysteresis loss. On the other hand, the $\mathrm{Ni}_{52.4} \mathrm{Mn}_{32.7} \mathrm{Cr}_{1} \mathrm{Sn}_{14}$ alloy surrenders to MPT at $223 \mathrm{~K}$ with $\Delta S_{M}{ }^{m a x}=1.7 \mathrm{~J} / \mathrm{kg} \cdot \mathrm{K}(1 \mathrm{~T})$. Although the $\Delta S_{M}$ in the $\mathrm{Ni}_{52.4} \mathrm{Mn}_{32.7} \mathrm{Cr}_{1} \mathrm{Sn}_{14}$ alloy spreads over a broad temperature window, it gives a much smaller $R C=16.2 \mathrm{~J} / \mathrm{kg}$ which still dwindled by $16.7 \%$ hysteresis loss compared to $\mathrm{Ni}_{49.6} \mathrm{Mn}_{37.3} \mathrm{Cr}_{0.7} \mathrm{Sn}_{12.4}$. These results are primarily ascribed to the weakened $\mathrm{Ni} / \mathrm{Mn}$ hybridization due to depleted $\mathrm{Mn}$ content in the $\mathrm{Ni}_{52.4} \mathrm{Mn}_{32.7} \mathrm{Cr}_{1} \mathrm{Sn}_{14}$ alloy.

Acknowledgments: Financial support by the Polish National Centre for Research and Development (Project number: PBS/A5/36/2013) is gratefully acknowledged.

Author Contributions: P. C., R. C., A. Ż., L. H., J. P. conceived and designed the experiments; P. C., R. C., A. Ż., L. H., J. P. performed the experiments; P. C., R. C. and J. P. analyzed the data; P. C. wrote the paper.

Conflicts of Interest: The authors declare no conflict of interest.

\section{References}

1. Planes, A.; Manosa, L.; Acet, M. Magnetocaloric effect and its relation to shape-memory properties in ferromagnetic Heusler alloys. J. Phys. Condens. Matter 2009, 21, 233201. [CrossRef] [PubMed]

2. Kainuma, R.; Imano, Y.; Ito, W.; Sutou, Y.; Morito, H.; Okamoto, S.; Kitakami, O.; Oikawa, K.; Fujita, A.; Kanomata, T.; Ishida, K. Magnetic-field-induced shape recovery by reverse phase transformation. Nat. Lett. 2006, 439, 957-960. [CrossRef] [PubMed]

3. Krenke, T.; Duman, E.; Acet, M.; Wassermann, E.F.; Moya, X.; Manosa, L.; Planes, A. Inverse magnetocaloric effect in ferromagnetic Ni-Mn-Sn. Nat. Lett. 2005, 4, 450-454. [CrossRef] [PubMed]

4. Sun, W.; Liu, J.; Lu, B.; Li, Y.; Yan, A. Large elastocaloric effect at small transformation strain in $\mathrm{Ni}_{45} \mathrm{Mn}_{44} \mathrm{Sn}_{11}$ metamagnetic shape memory alloys. Scr. Mater. 2016, 114, 1-4. [CrossRef]

5. Czaja, P.; Chulist, R.; Szczerba, M.J.; Przewoźnik, J.; Olejnik, E.; Chrobak, A.; Maziarz, W.; Cesari, E. Magnetostructural transition and magnetocaloric effect in highly textured Ni-Mn-Sn alloy. J. Appl. Phys. 2016, 119, 165102. [CrossRef]

6. Khan, M.; Dubenko, I.; Stadler, S.; Ali, N. Exchange bias in bulk Ni-Mn-Sn Heusler alloys. J. Appl. Phys. 2007, 102, 113914. [CrossRef]

7. Khan, M.; Pathak, A.K.; Paudel, M.R.; Dubenko, I.; Stadler, S.; Ali, N. Magnetoresistance and field-induced structural transitions in $\mathrm{Ni}_{50} \mathrm{Mn}_{50-} \mathrm{Sn}_{x}$ Heusler alloys. J. Magn. Magn. Mater. 2008, 320, L21-L25. [CrossRef]

8. Liu, J.; Gottschall, T.; Skokov, K.P.; Moore, J.D.; Gutfleisch, O. Giant magnetocaloric effect driven by structural transitions. Nat. Mater. 2012, 11, 620-626. [CrossRef] [PubMed]

9. Chernenko, V.A. Compositional instability of $\beta$-phase in Ni-Mn-Ga alloys. Scr. Mater. 1999, 40, 523-527. [CrossRef] 
10. Krenke, T.; Moya, X.; Aksoy, S.; Acet, M.; Entel, P.; Manosa, L.; Planes, A.; Elerman, Y.; Yucel, A.; Wassermann, E.F. Electronic aspects of the martensitic transition in Ni-Mn based Heusler alloys. J. Magn. Magn. Mater. 2007, 310, 2788-2789. [CrossRef]

11. Wang, X.; Shang, J.-X.; Wang, F.-H.; Jiang, C.-B.; Xu, H.-B. Origin of unusual properties in the ferromagnetic Heusler alloy Ni-Mn-Sn: A first-principles investigation. Scr. Mater. 2014, 89, 33-36. [CrossRef]

12. Wang, R.L.; Yan, J.B.; Xiao, H.B.; Xu, L.S.; Marchenkov, V.V.; Xu, L.F.; Yang, C.P. Effect of electron density on the martensitic transition in Ni-Mn-Sn alloys. J. Alloys Compd. 2011, 509, 6834-6837. [CrossRef]

13. Zhang, C.L.; Zou, W.Q.; Xuan, H.C.; Han, Z.D.; Wang, D.H.; Gu, B.X.; Du, Y.W. Giant low-field magnetic entropy changes in $\mathrm{Ni}_{45} \mathrm{Mn}_{44-x} \mathrm{Cr}_{x} \mathrm{Sn}_{11}$ ferromagnetic shape memory alloys. J. Phys. D Appl. Phys. 2007, 40, 7287-7290. [CrossRef]

14. Pandey, S.; Quetz, A.; Aryal, A.; Dubenko, I.; Mazumdar, D.; Stadler, S.; Ali, N. Large inverse magnetocaloric effects and giant magnetoresistance in Ni-Mn-Cr-Sn Heusler alloys. Magnetochemistry 2017, 3, 1-7. [CrossRef]

15. Sharma, V.K.; Chattopadhyay, M.K.; Nath, S.K.; Sokhey, K.J.S.; Kumar, R.; Tiwari, P.; Roy, S.B. The effect of substitution of $\mathrm{Mn}$ by $\mathrm{Fe}$ and $\mathrm{Cr}$ on the martensitic transition in the $\mathrm{Ni}_{50} \mathrm{Mn}_{34} \mathrm{In}_{16}$ alloy. J. Phys. Condens. Matter 2010, 22, 486007. [CrossRef] [PubMed]

16. Sharma, V.K.; Chattopadhyay, M.K.; Sharath, L.S.; Roy, S.B. Elevating the temperature regime of the large magnetocaloric effect in a Ni-Mn-In alloy towards room temperature. J. Phys. D Appl. Phys. 2011, 44, 145002. [CrossRef]

17. Sanchez-Alarcos, V.; Recarte, V.; Perez-Landazabal, J.I.; Chapelon, J.R.; Rodriguez-Velamazan, J.A. Structural and magnetic properties of Cr-doped Ni-Mn-In metamagnetic shape memory alloys. J. Phys. D Appl. Phys. 2011, 44, 395001. [CrossRef]

18. Khan, M.; Jung, J.; Stoyko, S.S.; Mar, A.; Quetz, A.; Samanta, T.; Dubenko, I.; Ali, N.; Stadler, S.; Chow, K. The role of Ni-Mn hybridization on the martensitic phase transitions in Mn-rich Heusler alloys. Appl. Phys. Lett. 2012, 100, 172403. [CrossRef]

19. Liu, J.; Woodcock, T.G.; Scheerbaum, N.; Gutfleisch, O. Influence of annealing on magnetic field-induced structural transformation and magnetocaloric effect in Ni-Mn-In-Co ribbons. Acta Mater. 2009, 57, 4911-4920. [CrossRef]

20. Oikawa, K.; Ota, T.; Gejima, F.; Ohmori, T.; Kainuma, R.; Ishida, K. Phase equilibria and phase transformations in new B2-type ferromagnetic shape memory alloys of Co-Ni-Ga and Co-Ni-Al systems. Mater. Trans. 2001, 42, 2472-2475. [CrossRef]

21. Cakir, A.; Acet, M.; Farle, M. Shell-ferromagnetism of nano-Heuslers generated by segregation under magnetic field. Sci. Rep. 2016, 6, 28931. [CrossRef] [PubMed]

22. Chen, F.; Tong, Y.X.; Li, L.; Llamazares, J.L.S.; Sanchez-Valdes, C.F.; Mullner, P. The effect of step-like martensitic transformation on the magnetic entropy change of $\mathrm{Ni}_{40.6} \mathrm{Co}_{8.5} \mathrm{Mn}_{40.9} \mathrm{Sn}_{10}$ unidirectional crystal grown with the Bridgman-Stockbarger technique. J. Alloys Compd. 2017, 691, 269-274. [CrossRef]

23. Ghosh, A.; Mandal, K. Effect of structural disorder on the magnetocaloric properties of Ni-Mn-Sn alloy. Appl. Phys. Lett. 2014, 104, 031905. [CrossRef]

24. Wang, R.L.; Xu, L.S.; Xiao, H.B.; Xu, L.F.; Zhang, J.X.; Chen, R.J.; Guo, S.; Yang, C.P. Effect of post-annealing on the phase transitions and magnetocaloric properties in bulk $\mathrm{Ni}_{44} \mathrm{Mn}_{45} \mathrm{Sn}_{11}$ alloy. J. Appl. Phys. 2013, 113, 17A936. [CrossRef]

25. Alvarez, P.; Gorria, P.; Llamazares, J.L.S.; Blanco, J.A. Searching the conditions for a table-like shape of the magnetic entropy in magneto-caloric materials. J. Alloys Compd. 2013, 568, 98-101. [CrossRef]

26. Han, Z.D.; Wang, D.H.; Zhang, C.L.; Xuan, H.C.; Gu, B.X.; Du, Y.W. Low-field inverse magnetocaloric effect in $\mathrm{Ni}_{50-x} \mathrm{Mn}_{39+x} \mathrm{Sn}_{11}$ Heusler alloys. Appl. Phys. Lett. 2007, 90, 042507. [CrossRef]

27. Ye, M.; Kimura, A.; Miura, Y.; Shirai, M.; Cui, Y.T.; Shimada, K.; Namatame, H.; Taniguchi, M.; Ueda, S.; Kobayashi, K.; et al. Role of electronic structure in the martensitic phase transition of $\mathrm{Ni}_{2} \mathrm{Mn}_{1+x} \mathrm{Sn}_{1-x}$ studied by hard-X-ray photoelectron spectroscopy and ab initio calculation. Phys. Rev. Lett. 2010, 104, 176401. [CrossRef] [PubMed]

28. Wang, X.; Shang, J.-X.; Wang, F.-H.; Jiang, Ch.-B.; Xu, H.-B. Effect of 3d transition elements substitution for $\mathrm{Ni}$ in $\mathrm{Ni}_{2} \mathrm{Mn}_{1+x} \mathrm{Sn}_{1-x}$ on the phase stability and magnetic properties: A first principle investigation. J. Magn. Magn. Mater. 2014, 368, 286-294. [CrossRef] 
29. Krenke, T.; Acet, M.; Wassermann, E.F.; Moya, X.; Manosa, L.; Planes, A. Martensitic transitions and the nature of ferromagnetism in the austenitic and martensitic states of Ni-Mn-Sn alloys. Phys. Rev. B 2005, 72, 014412. [CrossRef]

30. Lazpita, P.; Barandiaran, J.M.; Gutierrez, J.; Feuchtwanger, J.; Chernenko, V.A.; Richard, M.L. Magnetic moment and chemical order in off-stoichiometric Ni-Mn-Ga ferromagnetic shape memory alloys. New J. Phys. 2011, 13, 033039. [CrossRef]

31. Czaja, P.; Maziarz, W.; Przewoźnik, J.; Kapusta, C.; Hawelek, L.; Chrobak, A.; Drzymała, P.; Fitta, M.; Kolano-Burian, A. Magnetocaloric properties and exchange bias effect in Al for Sn substituted $\mathrm{Ni}_{48} \mathrm{Mn}_{39.5} \mathrm{Sn}_{12.5}$ Heusler alloy ribbons. J. Magn. Magn. Mater. 2014, 358-359, 142-148. [CrossRef]

32. Muthu, S.E.; Rao, N.V.R.; Rao, D.V.S.; Raja, M.M.; Devarajan, U.; Arumugam, S. Effect of Ni/Mn concentration on exchange bias properties in bulk $\mathrm{Ni}_{50-x} \mathrm{Mn}_{37+x} \mathrm{Sn}_{13}$ Heusler alloys. J. Appl. Phys. 2011, 110, 023904. [CrossRef]

33. Czaja, P.; Przewoźnik, J.; Gondek, Ł.; Hawelek, L.; Żywczak, A.; Zschech, E. Low temperature stability of $4 \mathrm{O}$ martensite in $\mathrm{Ni}_{49.1} \mathrm{Mn}_{38.9} \mathrm{Sn}_{12}$ metamagnetic Heusler alloy ribbons. J. Magn. Magn. Mater. 2017, 421, $19-24$. [CrossRef]

(C) 2017 by the authors. Licensee MDPI, Basel, Switzerland. This article is an open access article distributed under the terms and conditions of the Creative Commons Attribution (CC BY) license (http://creativecommons.org/licenses/by/4.0/). 